Evolution of the Postgraduate Medical Journal

Bernard M Y Cheung PhD, FRCP

Department of Medicine, University of Hong Kong, Hong Kong

Address for correspondence

Prof Bernard Cheung

University Department of Medicine

Queen Mary Hospital

Pokfulam Road

Hong Kong

Tel: +85222554347

Fax: +85228186474

Email: mycheung@hku.hk 


\section{Evolution of the Postgraduate Medical Journal}

Sir William Osler (1849-1919), sometimes called the 'Father of Modern Medicine', and has various diseases (e.g. Osler-Weber-Rendu syndrome), nodes, signs and worms, not to say schools and buildings, named after him, is also in many ways the father of modern medical education. He championed clinical clerkship for undergraduates and pioneered full-time live-in residency at Johns Hopkins. Osler's legacy is discussed in Terence Ryan's editorial in this issue. ${ }^{1}$ In 1911, when he was in England, Osler founded the Postgraduate Medical Association. After the First World War, the association merged with the Fellowship of Medicine to become the Fellowship of Postgraduate Medicine, with Osler as its first President. $^{2,3}$

The Fellowship founded the Postgraduate Medical Journal in 1925, with the aim of describing what postgraduate work is being done and to enable everyone to keep in touch with it. ${ }^{4}$ The first issue was prefaced by two editorials written by Sir William Hale-White and Sir Berkeley Moynihan, who were both eminent clinicians at the time. These editorials make for very interesting reading. 'Our fault is that we are apt to practise the medicine which we learnt in our student days,' wrote Moynihan. ${ }^{5}$ 'Some of us are content to ... read, and that only fitfully, one of the weekly journals, and an occasional volume of outstanding merit or of special application in our daily work.' He went on to recommend reading for a short period every day, attending meetings of a medical society and to join a postgraduate class. Hale-White sagely commented that 'experience has shown that undergraduates and post-graduates cannot always be satisfactorily taught together'. ${ }^{4}$ Their words of wisdom ring true even today. 
As the Postgraduate Medical Journal celebrates its $90^{\text {th }}$ Anniversary this year, it is time to reflect, take stock and look to the future. The PMJ has indeed been providing stimulating and clinically relevant articles for busy clinicians for ninety years and has organised or coorganised medical meetings and workshops. A special symposium to celebrate the 90th Anniversary is held in London on 1 October, with a distinguished line-up of speakers to review the most important advances in their respective disciplines. Together with this special issue of PMJ, we will collectively look at the past in order to see the future.

The future of the PMJ is best thought of in evolutionary terms. Evolution is an adaptive response to a changing environment in order to survive, grow and prosper. Nowadays, dissemination of information is predominantly electronic. This means that a massive amount of information can be sent or distributed instantly to a vast number of recipients in an environmentally friendly way. We can't turn back the clock and produce only glossily printed volumes; we need to embrace the new technologies and the new horizons. While the contents remain as rigorous as ever, the ways of presenting information can benefit from advances in technology. The present generation of young doctors grew up with social media, which is both a challenge and an opportunity for medical journals. In this issue, Toby Hillman discusses the impact and possibilities of social media in continuous medical education. $^{6}$

The primary mission of PMJ is to serve a target readership of junior doctors and their teachers. When I was a junior doctor, unusual presentations and rare diseases were presented in grand rounds and written up as case reports. Clinical training is now more focussed on core competencies and the ability to manage common conditions safely. In the 
last two decades or so, treatments and management strategies have gained a firm scientific basis through randomised controlled trials, meta-analysis and Cochrane reviews. These provide the evidence for management guidelines and pathways that help to guide doctors, particularly those in training, to manage common conditions safely and effectively. The PMJ would continue to welcome the publication of clinical trials, meta-analysis and systematic reviews, and also to invite reviews on contemporary management of common conditions. These articles would be very valuable for the training of junior doctors and for the continuous professional development of established doctors. We particularly welcome junior authors partnering with senior authors to produce articles that are at once authoritative and of interest to postgraduates.

The internet, which is now accessible in most countries in the world, has resulted in instantaneous dissemination of information throughout the world, to an ever widening world population that read and understand English. There are two consequences. Firstly, rapid publication is now expected by both authors and readers. Secondly, the PMJ must reach out to different parts of the world. Clinical medicine and research in China, for instance, is expanding rapidly. As said by Moynihan, 'learning, both in acquisition and display, is made more attractive by sharing it with others' ${ }^{5}$

Osler had an outrageous sense of humour and titled his farewell speech 'The Fixed Period', which spawned the headline 'Osler recommends chloroform at sixty'. A ninety-year-old journal is in danger of being seen as past its prime or even fossilised. The PMJ will therefore constantly evolve and re-invent itself. Evolution has served life on earth well in 
the last 3.6 billion years. I am optimistic that the PMJ will undergo renewal and regeneration, and retain a unique niche in the publishing jungle.

Bernard Cheung

August 2015

Competing interests: none

\section{References}

1. Ryan TJ. Osler and his teaching: relevant today. Postgrad Med J 2015;xxx.

2. Cook GC. History of the Postgraduate Medical Journal. Postgrad Med J 2005;81:673.

3. Singer DRJ. Nine decades for the Fellowship of Postgraduate Medicine. Postgrad Med J $2008 ; 84: 2$

4. Hale-White W. Foreword. Postgrad Med J 1925; 1: 1.

5. Moynihan B. Foreword. Postgrad Med J 1925; 1: 1.

6. Hillman T. Social media: a new pedagogy. Postgrad Med J 2015;xxx. 